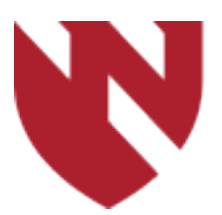

September 2020

\title{
Are We Missing Vitamin Deficiencies in Parkinson's Disease?
}

\author{
Praveen Hariharan \\ University of Nebraska Medical Center \\ Erin L. Smith \\ University of Nebraska Medical Center \\ Nabeel M. Syed \\ University of Nebraska Medical Center \\ Bobbi J. Roeder \\ University of Nebraska Medical Center \\ Jenna Paseka \\ University of Nebraska Medical Center
}

See next page for additional authors

Tell us how you used this information in this short survey.

Follow this and additional works at: https://digitalcommons.unmc.edu/gmerj

Part of the Higher Education Commons, and the Medicine and Health Sciences Commons

\section{Recommended Citation}

Hariharan, P., Smith, E. L., Syed, N. M., Roeder, B. J., Paseka, J., Bhatti, D., Torres-Russotto, D. R., , Bertoni, J. M. Are We Missing Vitamin Deficiencies in Parkinson's Disease?. Graduate Medical Education Research Journal. 2020 Sep 29; 2(1).

https://digitalcommons.unmc.edu/gmerj/vol2/iss1/81

This Conference Proceeding is brought to you for free and open access by DigitalCommons@UNMC. It has been accepted for inclusion in Graduate Medical Education Research Journal by an authorized editor of DigitalCommons@UNMC.For more information, please contact digitalcommons@unmc.edu. 


\section{Are We Missing Vitamin Deficiencies in Parkinson's Disease?}

Creative Commons License

(c) (i)@(ङ)

This work is licensed under a Creative Commons Attribution-Noncommercial-No Derivative Works 4.0 License.

\section{Authors}

Praveen Hariharan, Erin L. Smith, Nabeel M. Syed, Bobbi J. Roeder, Jenna Paseka, Danish Bhatti, Diego R. Torres-Russotto, and John M. Bertoni 
Conclusion: CPM and QM set by ACC/AHA are not always met during care of post-AMI patients. One common barrier is documenting contraindications to recommended therapies. Quality improvement projects should be implemented to optimize the rate of CPM and QM met.

https://doi.org/10.32873/unmc.dc.gmerj.2.1.058

\section{Right Ventricular Lead Dysfunction Post LVAD Implantation}

Ahmed Mohamed Abdelhalim-Selim¹, Rahul Dhawan', Katheine Germann¹, Scott Lundgren'1, Ronald Zolty ${ }^{1}$, Faris Khan ${ }^{1}$

${ }^{1}$ University of Nebraska Medical Center, Department of Internal Medicine, Division of Cardiovascular Disease

\section{Mentor: Faris Khan}

Program: Internal Medicine, Division of Cardiovascular Disease

Type: Original Research

Background: The use of left ventricular assist devices (LVAD), both as bridge to cardiac transplantation as well as destination therapy, has increased significantly over the last few years. The vast majority of these patients are eligible for electrical implantable devices (including single, dual chamber, and biventricular defibrillators). There is scarcity of data on the impact of LVAD placement on the right ventricular lead integrity in these devices

Methods: We studied a total of 50 patients who had implantable cardioverter device (single, dual chamber and biventricular device) prior to LVAD placement at the University of Nebraska between 2017 and 2019, a chart review was done to identify patients with right ventricular lead dysfunction that was diagnosed post LVAD implantation.

Results: The mean age of patients at the time of LVAD was $54(+/-14)$ years, the study included 41 males $(82 \%)$. Forty-two patients had Heartmate III, four had Heartmate II and four patients had Heartware LVAD.
Twenty seven patients had single or dual chamber ICD (54\%) while 23 patients had a biventricular ICD (46\%). Right ventricular lead malfunction was reported in 18 patients (36\%) within 6 months of LVAD implantation. The type of left ventricular assist devices and electrical devices were not significantly

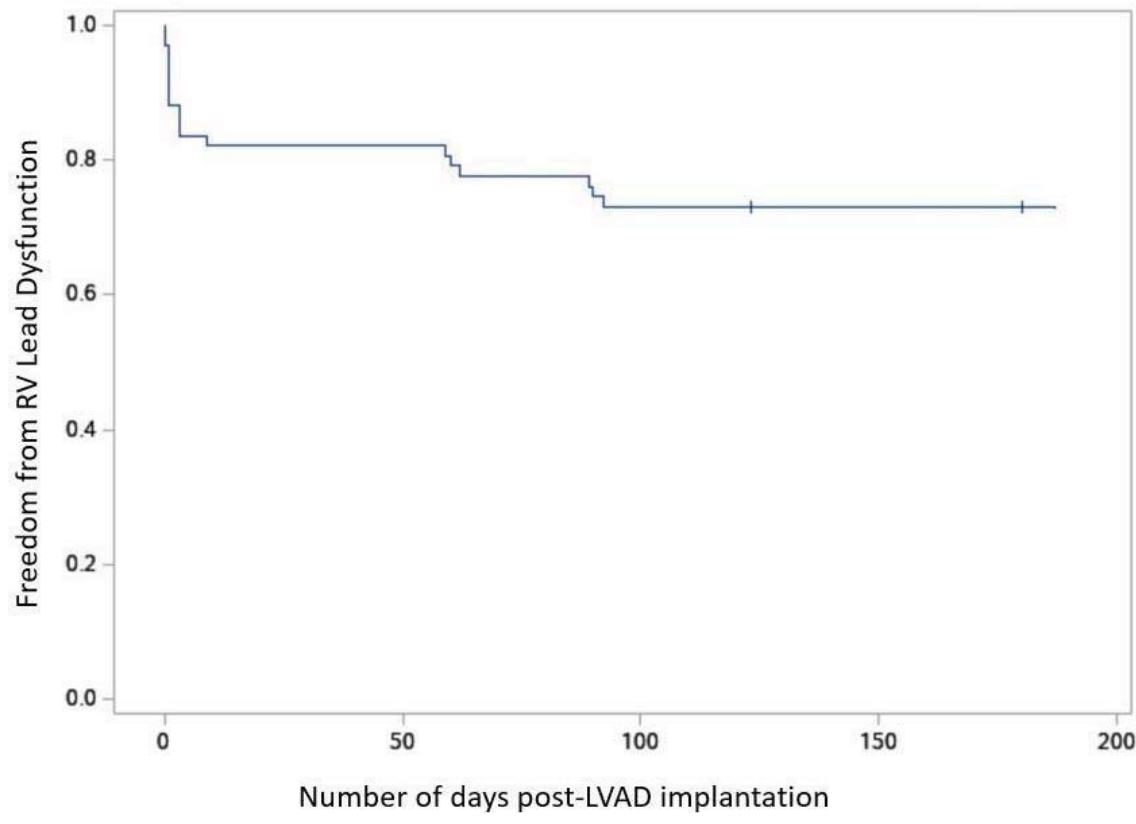

Figure 1. ICD* lead malfunction in first 6 months after LVAD* implant. *ICD: Implantable Cardioverter Defibrillator; LVAD: Left Ventricular Assist Device. different in the RV lead malfunction group compared to the rest of the patients.

Conclusion: There is a high incidence of right ventricular lead dysfunction post implantation of left ventricular assist devices.

https://doi.org/10.32873/unmc.dc.gmerj.2.1.078

\section{Are We Missing Vitamin Deficiencies in Parkinson's Disease?}

Praveen Hariharan ${ }^{1}$, Erin L. Smith², Nabeel M. Syed ${ }^{2}$, Bobbi J. Roeder ${ }^{2}$, Jenna Paseka ${ }^{1}$, Danish Bhatti ${ }^{2}$, Diego R. Torres-Russotto ${ }^{2}$, John M. Bertoni ${ }^{2}$ ${ }^{1}$ University of Nebraska Medical Center, Department of Neurological Sciences

${ }^{2}$ University of Nebraska Medical Center, Department of Neurological Sciences, Division of Movement Disorders

Mentor: John M. Bertoni

Program: Neurological Sciences, Division of Movement Disorders

Type: Case Report

Background: Parkinson's disease (PD) management focuses on quality of life, including adequate nutrition. Extensive literature has correlated nutritional deficiencies and PD, but they are still commonly missed. Many new neurological symptoms are attributed to disease progression without ruling out these treatable conditions.

Methods: We present three cases of PD patients with diverse neurological symptoms whose workup showed reversible vitamin deficiencies.
Results: Case 1 This 81-year-old male physician with PD developed weight loss, irritability, and dementia attributed to advanced disease. Workup revealed low thiamine (B1) of $30 \mathrm{nmol} / \mathrm{L}$ (70-180), pyridoxine (B6) of $5.2 \mathrm{nmol} / \mathrm{L}$ (20.0-125.0), cobalamin (B12) of $72 \mathrm{pg} / \mathrm{mL}(180-914)$, and 25-hydroxyvitamin D of $14 \mathrm{ng} / \mathrm{mL}$ (30-80). He was noncompliant with replacement and passed away. Case 2 This 90-year-old woman 
with PD developed acute confusion and visual hallucinations of butterflies ascribed to PD. She was considered for discharge until a dietary history revealed that a typical meal was diet soda and white bread. Serum B1 (49 nmol/L), B6 (<5.0 nmol/L), and folate $(5.4 \mathrm{ng} / \mathrm{mL})$ were low. Confusion and hallucinations resolved three days after replacement. Case 3 This 46-year-old policeman with PD presented for a second opinion in the Comprehensive PD Clinic. He complained of trouble walking and forgetfulness thought related to his PD. B12 was low $(176 \mathrm{pg} / \mathrm{mL})$ and normalized with replacement. Symptoms resolved within eight weeks.

Conclusion: Common symptoms of PD including gait problems, cognitive impairment, hallucinations, and sensory disturbances can be caused by vitamin deficiencies and are easily correctable. We are currently collecting nutritional data on our PD patients for future studies.

https://doi.org/10.32873/unmc.dc.gmerj.2.1.079

\section{Vitamin Deficiencies Are Extremely Common in Parkinson's Disease: A Case for Routine Screening Erin L. Smith', Jenna Paseka', Danish Bhatti', Diego R. Torres-Russotto', John M. Bertoni² \\ ${ }^{1}$ University of Nebraska Medical Center, Department of Neurological Sciences, Division of Movement Disorders \\ ${ }^{2}$ University of Nebraska Medical Center, Department of Neurological Sciences}

Mentor: John M. Bertoni

Program: Neurological Sciences, Division of Movement Disorders

Type: Original Research

Background: In this study we assess vitamin deficiencies in Parkinson's disease (PD) and their impact on disease characteristics and common clinical assessments.

Methods: 118 patients from our PD clinic underwent serum testing for thiamine (B1), pyridoxine (B6), cobalamin (B12) and 25-hydroxy cholecalciferol (D3). We compared age, BMI, disease duration, United Parkinson's Disease Rating Scale (UPDRS), Mini Mental Status Examination (MMSE), levodopa equivalent daily dose (LEDD), and reported falls between those with and without vitamin deficiencies. Statistical analyses included a nonparametric Wilcoxon twosample test and nonparametric Pearson and Spearman correlations.

Results: In total, 66 patients $(56 \%)$ were deficient in one vitamin, and 24 in two or more $(\mathrm{B} 1=6, \mathrm{~B} 6=26, \mathrm{~B} 12=44$, and $\mathrm{D} 3$ $=24)$. Average UPDRS score was 35 with average disease duration of 7 years for both groups. LEDD for deficient patients was higher $(712 \mathrm{mg}$ ) compared to the normal group (594 mg), though not statistically significant $(\mathrm{p}=0.11)$. There was a trend for older age in the deficient group (73 vs 69.5 years; $\mathrm{p}=0.093$ ). Both groups had similar MMSE scores and report of falls. There were no linear correlations between vitamin levels and age, BMI, disease duration, UPDRS, MMSE, or LEDD.

\section{Models of Pediatric Asthma Care Alamelu Udayappan ${ }^{1}$, Chad Abersch ${ }^{2}$}

${ }^{1}$ University of Nebraska Medical Center, Department of Pediatrics

${ }^{2}$ University of Nebraska Medical Center, CityMatCH

\section{Mentor: Chad Abersch}

Program: Pediatrics

Type: Review/Meta-analysis

Background: Asthma exacerbation is a leading cause of emergency department visits and one of the top indications for hospitalization in children. Not only does this burden the medical care system with accruing costs and resources, these exacerbations are highly preventable given a strong medical home and a practical model of pediatric asthma care. Our aim was to perform a systemic review of literature to evaluate the existent models of pediatric asthma care with clinical and public health outcomes.

Methods: The Up to Date, Cochrane Library, and PubMed databases were queried using the search terms "Models of Pediatric Asthma Care". We included all original, full-text abstracts published after 2010. We excluded abstracts pertaining to novel agents in treatment, ED/inpatient management, schoolbased protocols, complementary/alternative medication, environmental and epigenetic factors.

Results: The proposed models in literature are as follows:

1. Subgroup Analyses from the Prompting Asthma Intervention in RochesterUniting Parents and Providers Trial (Goldstein et all, 2018).

2. Children's Hospital Boston Community Asthma Initiative (Sommer et all, 2011).

3. Medical Home Model (Rojanasarot et all, 2018).
Conclusion: Our preliminary data suggest that although vitamin deficiencies were present in $56 \%$ of our PD patients, there was not a strong correlation between serum levels and objective clinical measurements. Sample size limited statistical power and we will repeat analyses as more patients are enrolled. There are many other objective measures that can be included in future studies.

https://doi.org/10.32873/unmc.dc.gmerj.2.1.080

4. Ensemble Learning Model (Khasha R et all, 2019).

5. Practice Organization Model (Ruffner MA et all, 2018).

Conclusion: Asthma continues to be a major public health problem despite novel treatment agents and guideline-based management. An ideal theoretical model would include a) family educational programs/community resources, b) severity/control assessment, d)ensuring access of medication/ insurance coverage, e) addressing environmental triggers, f)frequent follow up care for susceptible children, g) addressing co-morbid conditions, and h) implementing legislative policy change.

https://doi.org/10.32873/unmc.dc.gmerj.2.1.082 